\title{
CLASSIFIED NOTICES
}

Personnel ads only. Box number service is not available; the name and address of the agency must appear. Rate is $\$ 3$. per line. Closing date six weeks before month of issue.

CALIFORNIA, Hemet-Community Mental Health Center has an immediate need of a STAFF PSYCHIATRIST. This facility offers a full range of psychiatric services and a variety of clinical experience. Excell. salary with benefit pkg that includes pd vacation, holidays, sick leave, life ins., health ins., and retirement. Deferred comp also offered. Hemet is approx. $85 \mathrm{mi}$. NE of San Diego at the foot of the San Jacinto $\mathrm{mts}$. Lakes, beaches, $\mathrm{mt}$. resorts, golf, racetracks, Palm Springs and other rec. resort areas are within $1 \mathrm{hr}$. driving time. Hemet's country setting makes freeway traffic jams a thing of the past. Call or write Myron L. Grindheim, Director of Personnel, Hemet Valley Hospital, 116 E. Latham Av., Hemet, Cal. 92343 (714) 652-2811.

CONNECTICUT, Middletown-PSYCHIATRISTS-Exciting opportunity for dynamic part-time or full-time psychiatrists; consult, diagnose, and treat adolescents in expanding psychiatric facility; faculty appointment available. Must be board certified or licensed or eligible for license to practice psychiatry in Connecticut. Salary commensurate with experience, plus excellent fringe benefits. Direct resumes to Superintendent, Adolescent Unit, Connecticut Valley Hospital, P.0. Box 351, Middletown, Connecticut 06457.

NEW YORK-OFFICE SPACE-Fifth Avenue, 9th Street. Luxurious, sound-proofed office with shared furnished waiting space, bath, private street entrance Call 673-6737.

OHIO, Columbus-CHILD PSYCHIATRIST needed as Medical Director of combined inpatient-outpatient Children's Mental Health Center. Need someone with clinical and administrative experience. Also involved with Child Psychiatry program located within University Medical Center with clinical, administrative and teaching appointments. Contact Bruce Meyer, M.D., Children's Mental Health Center, Inc., 721 Raymond Street, Columbus, Ohio 43205.

TEXAS, Lubbock-MEDICAL DIRECTOR-Salary up to $\$ 45,200$ annually. Requires at least eight (8) years experience in Psychiatry, Board Certified and Licensed to practice in Texas. Will have considerable latitude in the execution of clinical judgment. Position available January 1, 1978. AM/EEO Employer. The Lubbock Regional MHMR Center, 1210 Texas Avenue, Lubbock, Texas 79401.

TEXAS, Lubbock_PSYCHIATRIST \|-Salary up to $\$ 43,100$ annually. Requires M.D. degree; one year internship and three (3) years residency in Psychiatry. Position available immediately. AA/EEO Employer. The Lubbock Regional MHMR Center, 1210 Texas Avenue, Lubbock, Texas 79401.

WEST_-PSYCHIATRISTS needed in Alaska, Idaho, Oregon and Washington, Positions available in Community Mental Health Centers. Nonprofit organization is coordinating recruitment under federal grant. For information contact: The Community Health Center Clearing-House, 1370 str " " nattle, WA 98109 or call (206) 63 